\title{
Relating the occurrence of crevasses to surface strain rates
}

\author{
DAVID G. VAUGHAN \\ British Antarctic Survey, Natural Environment Research Council, Cambridge CB3 OET, England
}

\begin{abstract}
The presence of crevasses on the surface of ice masses indicates that a fracture criterion has been met. Understanding how crevasses form will provide information about the stress and strain-rate fields in the ice. This study derives a relationship between measurements of strain rate and observations of crevassing on the surface of ice masses. A literature search yielded 17 polar and alpine locations where strain rates had been measured and crevassing recorded. By plotting strain rates (converted to stresses using a creep law) using axes representing the surfaceparallel principal stresses, failure envelopes were derived by enclosing measurements where surface crevassing was absent. The derived failure envelopes were found to conform well to theoretical ones predicted by the Coulomb and the maximum octahedral shear stress (von Mises) theories of failure. The derived failure envelopes were scaled by the tensile strength, which was found to vary from 90 to $320 \mathrm{kPa}$. There was no systematic variation of tensile strength with either temperature at $10 \mathrm{~m}$ depth or the method used to locate the crevasses. The observed variation in tensile strength could result from variations in ice properties (e.g. crystal size, impurity content or density) or could be related to uncertainty in the constitutive relation. Creep flow and fracture share a very similar temperature dependence, suggesting similar crystal-scale processes are responsible for both. The observed relationship will provide a supplementary tool with which to verify and test models of ice dynamics against remotely sensed imagery. The study also indicates that a temperature rise of a few degrees throughout the ice column will not result directly in any increase in calving rates from the large Antarctic ice shelves such as the Filchner-Ronne or Ross Ice Shelves.
\end{abstract}

\section{INTRODUGTION}

Crevasses are seen frequently on the surface of glaciers and ice sheets. A better understanding of the conditions which give rise to crevassing would give valuable information about the fracture properties of ice and, particularly if a critical strain-rate or stress-fracture criterion exists, would also provide a constraint to be satisfied by mathematical models. As laboratory experiments have not yet reproduced the conditions experienced in the field, there are no reliable fracture theories of ice to predict the onset of crevassing. The aim here is to take a phenomenological approach by analysing the association between the presence (or absence) of crevassing and measured strain rates. The literature has been searched for suitable sets of strain-rate measurements in areas where their proximity to crevassing can be determined by reference to maps, diagrams, imagery and visual reports. These data sets were analysed to derive a criterion for the prediction of crevassing based on the principal stresses in the ice mass and temperature of the ice sheet.

A number of field studies of crevasses (e.g. Meier 1958; Holdsworth, 1969; Sharp and others, 1988) have attempted to explain the formation of crevasses by analysis of the exact conditions under which they occur.
In each case, considerable effort was made in the instrumentation of individual crevasses and small areas. Each study has explained crevassing in the light of the data collected, but they are in no way sufficient to formulate general laws. Hughes (1983) discussed the formation of crevasses on a wider scale and described a classification of crevassing based on tectonic style, but he did not relate his observations to any directly measured parameters.

Kehle (1964) explored analogues between the failure of ice and rock. His analysis of surface strain-rate data collected at the Bay of Whales, Antarctica, is similar to that presented here. In both cases, the central assumption is that crevasses are fractures that form once critical conditions of stress or strain rate are reached in the surface layers of an ice mass. Strain-rate data are converted to stress and plotted on axes of principal stress to produce a failure map. Kehle's results showed a good separation between data from crevassed and uncrevassed areas and were compatible with the rough form and shape of the failure surface which he postulated (Fig. 1). This study analyses more data sets and examines some of the theoretical failure surfaces that describe the results.

Fracture studies of polycrystalline ice in the laboratory (e.g. Butkovich, 1954; Jones, 1982; Schulson, 1984; Rist and others, 1988) are generally conducted at stresses high 


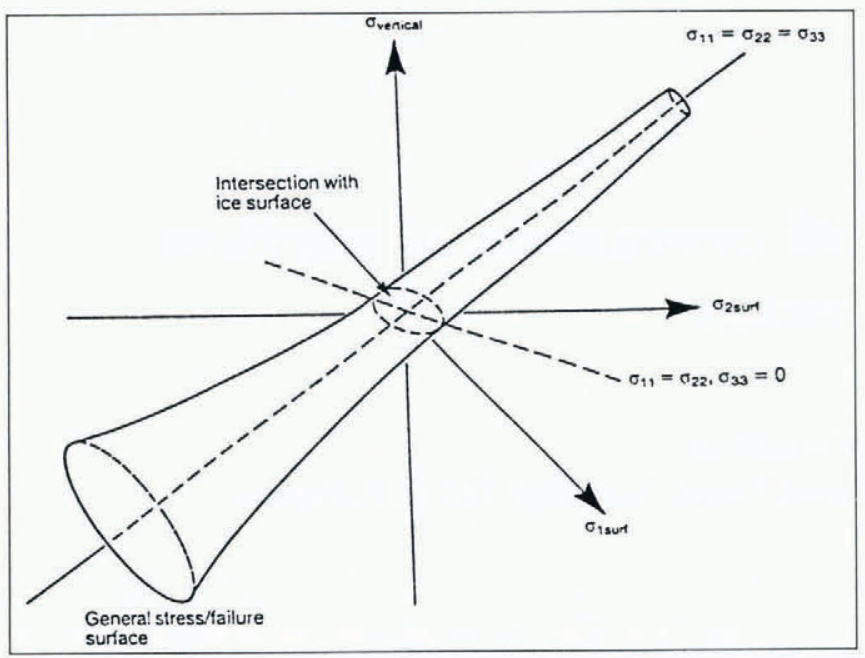

Fig. 1. The relation between the Kehle three-dimensional failure surface and that to be found on the surface of an ice mass.

enough $(1-10 \mathrm{MPa})$ to cause failure within a few hours or days. Natural ice masses experience moderate or low stresses $(0.01-0.1 \mathrm{MPa})$ for tens or hundreds of years and crevassing may be a product of these long stress histories. Samples tested in the laboratory are usually grown artificially and have densities similar to those found deep in natural ice masses, considerably greater than those of the firn in which surface crevasses occur. This discrepancy between the conditions of laboratory studies and of natural crevasse formation precludes a failure criterion based on laboratory experiments being applied to the interpretation of the occurrence of crevasses.

The viscous nature of ice and the increasing overburden with depth means that crevasses rarely penetrate more than $30 \mathrm{~m}$ in temperate glaciers (Paterson, 1981, p. 228), although they may be deeper if flooded by surface water (Weertman, 1973). Deeper crevasses can also occur in colder ice in the polar regions. The surface firn-layers in which crevasses form are the least dense and coldest part of ice masses and are subject to considerable variation in physical properties. For these reasons, the mechanical properties of firn (Perla and others, 1982) are poorly parameterized and, for the present study, it is not possible to specify the exact nature of the stress in this layer. Rather, the stress in the deeper layers of the ice and its influence on surface crevassing is emphasized.

A model is adopted in which the firn acts as a thin surface layer that contributes little to the depth-integrated strength of the ice mass. It is then assumed that the horizontal strain rate measured at the surface does not differ significantly from that in the main body of the ice below the crevasses (i.e. the firn is constrained to strain at the same rate as the denser ice beneath it). The firn layer fractures to form crevasses at some critical strain rate, regardless of previous stress history; this strain rate is controlled by the strain rate in the deep ice which, in turn, is determined by the stress and constitutive relation in the deep ice. The relation between surface crevassing and stress at depth is pursued in this study, particularly as it has direct relevance to mathematical models of ice masses which resolve only rarely the firn layer as having distinct properties.

\section{FAILURE OF ICE}

When ice is deformed under increasing stress, it undergoes a transition from elastic to ductile behaviour. At higher stresses, it becomes brittle and its ability to resist load decreases with increasing deformation. Fracture is a continuous process throughout the brittle regime until sudden failure occurs (Jaeger and Cook, 1979, p. 80). On a stress-strain diagram, the maximum stress occurs at the ductile/brittle transition, which may be considered a critical stress for failure.

Crevasse formation is a three-dimensional problem and is therefore described in terms of the three principal stresses, $\sigma_{11}, \sigma_{22}$ and $\sigma_{33}$, defined here to be such that $\sigma_{11}>\sigma_{22}>\sigma_{33}$, with tensional stress being positive. At the free surface of an ice mass, normal stress and traction are zero. This boundary condition forces one of the principal stresses to be normal to the surface and equal to zero. The zero normal stress may be any one of the maximum, intermediate or minimum principal stresses. The other two principal stresses (denoted here $\sigma_{1 \text { surf }}$ and $\left.\sigma_{2 \text { surf }}\right)$ are therefore parallel to the surface, and together with the surface-boundary condition, give a complete description of the stress field.

Many analyses of deformation mechanisms make use of Mohr diagrams, in which the maximum tensile stress $\left(\sigma_{11}+\sigma_{33}\right)$ is plotted against the maximum shear stress $\left(\sigma_{11}-\sigma_{33}\right)$. The Mohr representation is often favoured because it is a convenient way of contracting a threedimensional stress tensor on to the two most important axes at any one point. Thus, in a three-dimensional stress field, the Mohr axes have no constant spatial orientation and do not give a complete description of the stress field, ignoring as they do the intermediate principal stress. Open crevasses penetrate roughly perpendicularly to the ice surface, parallel to the zero principal stress. The orientation of a crevasse is controlled by $\sigma_{1 \text { surf }}$ and $\sigma_{2 \text { surf }}$, which, if they have the same sign, do not correspond to the maximum and minimum principal stresses. The intermediate principal stress cannot, therefore, be ignored when describing crevassing and the Mohr diagram is not an appropriate tool.

A failure map is a two-dimensional cross-section of a three-dimensional failure surface delineating the division between stress regimes where failure does and does not occur. Failure maps are presented here in terms of the two surface-parallel principal stresses (SPPS, $\sigma_{1 \text { surf }}$ and $\sigma_{2 \text { surf }}$ ), remembering that these may be any combination of maximum, intermediate or minimum stress. By exploiting the free-surface boundary condition, the maximum informational content is retained. This point is emphasized in Figure 2, which shows a number of points plotted on both the SPPS axes and the equivalent Mohr diagram. It is clear that the failure map using the SPPS system shows a failure envelope which maintains geometric information that is lost in the Mohr diagram.

\section{FAILURE MECHANISMS}

Kehle (1964) postulated a general three-dimensional failure surface for ice (Fig. 1) with rotational symmetry around the axis $\sigma_{11}=\sigma_{22}=\sigma_{33}$. The surface had a 


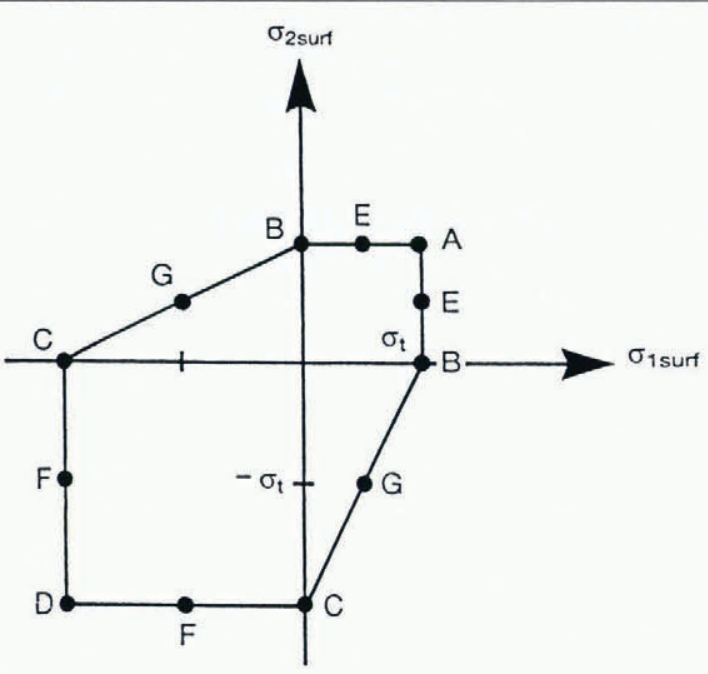

a

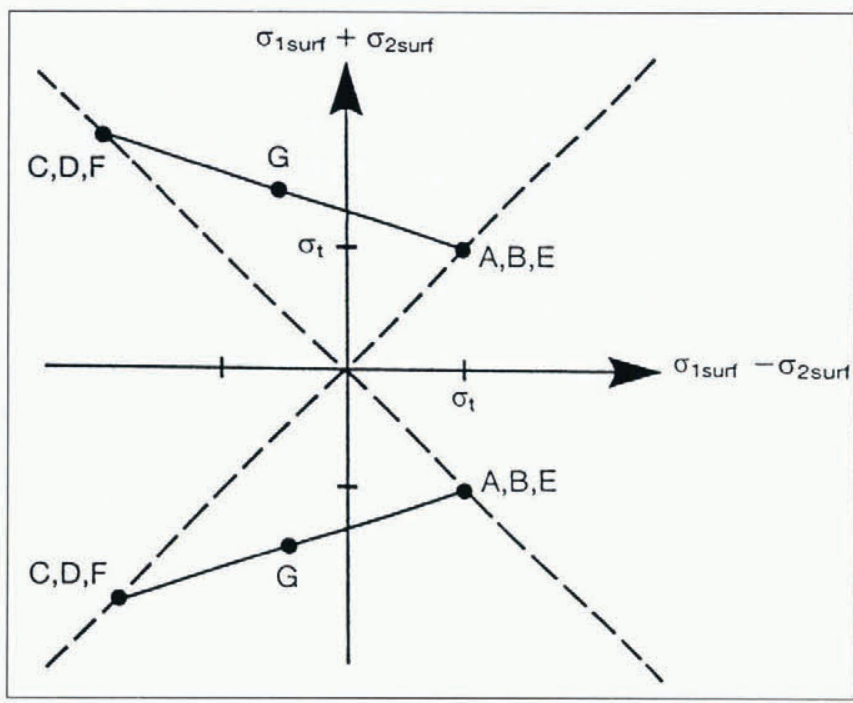

b

Fig. 2. Schematic comparison of (a) the SPPS and (b) the Mohr axial systems for ice-surface measurements. Points $A-E$ are plotted on both sets of axes and show the reduced usefulness of the Mohr system where the freesurface boundary-condition applies.

characteristic funnel shape, implying that failure requires higher stresses under increasing hydrostatic pressure (Nadreau and Michel, 1986; Hallam and Ashby, 1990). This feature adds considerable complexity to the failure envelope and is not considered in this study, which concentrates on near-surface conditions where the hydrostatic pressure is usually around zero.

The locus of intersection of a failure surface with the ice surface is found algebraically by setting one component of principal stress equal to zero. The failure map obtained for the generalized failure surface would be roughly elliptical but elongated in the third quadrant.

Little is known about the precise mechanisms leading to the failure of ice during crevassing; in postulating the form of suitable failure envelopes, it is reasonable to consider only the simplest forms with a sound phenomenological basis. Consideration is given to a number of forms that may be scaled using only one parameter, here chosen as the tensile strength $\left(\sigma_{t}\right)$. Their intersection with the ice surface is derived by application of the free-surface boundary condition (i.e. zero normal stress).
Maximum octahedral shear stress (von Mises) criterion

This failure criterion assumes that the material can support only a limited octahedral shear stress before failure. Initially proposed by von Mises (Ramsay, 1967) for ductile yield, this criterion has, however, been applied successfully to many systems where failure is not strictly by ductile yield. Algebraically, it is most easily expressed as a limiting value on the second invariant $\left(I^{\prime}{ }_{2}\right)$ of the deviatoric stress tensor $\sigma_{i j}^{\prime}$

$$
I_{2}^{\prime 2}=\frac{1}{6}\left[\left(\sigma_{11}-\sigma_{22}\right)^{2}+\left(\sigma_{22}-\sigma_{33}\right)^{2}+\left(\sigma_{33}-\sigma_{11}\right)^{2}\right]
$$

where, by definition,

$$
\sigma_{i j}^{\prime}=\sigma_{i j}-\frac{1}{3} \delta_{i j} \sigma_{k k} .
$$

The failure surface takes the form of a cylinder whose axis is parallel to $\sigma_{11}=\sigma_{22}=\sigma_{33}$ in stress space. Applying the free-surface boundary condition (e.g. $\sigma_{11}=\sigma_{1 \text { surf }}$, $\sigma_{22}=0, \sigma_{33}=\sigma_{2 \text { surf }}$ ) the von Mises criterion becomes:

$$
\sigma_{\mathrm{t}}^{2}=\sigma_{1 \text { surf }}^{2}+\sigma_{2 \text { surf }}^{2}-\sigma_{1 \text { surf }} \sigma_{2 \text { surf }}
$$

where $\sigma_{\mathrm{t}}$ may be interpreted as the tensile strength.

\section{Coulomb criterion}

The Coulomb criterion was developed initially to model shear failure in rocks and best describes granular materials where failure occurs by shearing along a fault plane. The material is characterized by a maximum shear stress $\left(S_{0}\right)$ which is enhanced by a coefficient of internal friction $(\mu)$

$$
\left|\left(\sigma_{11}-\sigma_{33}\right)\right|=S_{0}+\mu\left(\sigma_{11}+\sigma_{33}\right) .
$$

MacAyeal and others (1986) modelled ice-stream and iceshelf margins as shear boundaries obeying a Coulombfailure criterion. It is not obvious that the formation of crevasses should be considered in terms of shear failure because their orientation, and presumably their initial displacement, are most frequently perpendicular to the maximum principal stress. Because most strain-rate measurements are made on the 100 to $1000 \mathrm{~m}$ length scales, it is unlikely that the behaviour of individual crevasses should concern us. For this study, MacAyeal is followed by adopting a value for $\mu$ of 0.1 .

Applying the free-surface boundary condition, the Coulomb criterion becomes

$$
\begin{gathered}
\sigma_{1 \text { surf }}=S_{0} /(1-\mu) \\
\text { where } \sigma_{1 \text { surf }} \geq 0 \text { and } \sigma_{2 \text { surf }} \geq 0 \\
\sigma_{1 \text { surf }}=\left(S_{0}+\sigma_{2 \text { surf }}(1+\mu)\right) /(1-\mu) \\
\text { where } \sigma_{1 \text { surf }} \geq 0 \text { and } \sigma_{2 \text { surf }} \leq 0 \\
\sigma_{2 \text { surf }}=-S_{0} /(1+\mu) \\
\text { where } \sigma_{1 \text { surf }} \leq 0 \text { and } \sigma_{2 \text { surf }} \leq 0 .
\end{gathered}
$$

The commonly used Tresca criterion is a special case of the Coulomb criterion, in which the coefficient of internal friction is assumed to be zero. The failure surface for this criterion is a hexagonal prism lying with its axis along $\sigma_{11}=\sigma_{22}=\sigma_{33}$, producing a distorted hexagon on the plane $\sigma_{33}=0$ (i.e. the ice surface). 


\section{Griffith's criterion}

The theory of Griffith failure is based on the existence within a material of a high density of coin-shaped cracks which cause concentration of stress and failure at their edges. Ice at shallow depth contains a large number of intercrystalline pores, which, although they do not have the coin shape of classical Griffith cracks, have been shown to be the initiation sites for failure in polycrystalline ice at temperatures between $-25^{\circ}$ and $-50^{\circ} \mathrm{C}$ (Schulson and others, 1989).

The plane Griffith criterion given by Jaeger and Cook (1979, p. 101, noting the opposite-sign convention on stresses) may be reduced using the ice-surface boundary condition to

$$
\begin{array}{ll}
\sigma_{1 \text { surf }}=\sigma_{\mathrm{t}} & \text { where } \sigma_{1 \text { surf }} \geq 0 \\
\left(\sigma_{1 \text { surf }}-\sigma_{2 \text { surf }}\right)^{2}=-8 \sigma_{\mathrm{t}}\left(\sigma_{1 \text { surf }}+\sigma_{2 \text { surf }}\right) \\
\text { where } \sigma_{1 \text { surf }} \geq 0 \\
\text { and }\left(\sigma_{1 \text { surf }}+3 \sigma_{2 \text { surf }}\right) \leq 0 \\
\sigma_{2 \text { surf }}=-8 \sigma_{\mathrm{t}} & \text { where } \sigma_{1 \text { surf }} \leq 0 \\
& \text { and } \sigma_{2 \text { surf }} \leq 0 .
\end{array}
$$

This criterion produces a failure envelope that is elongated considerably in the third quadrant, indicating that failure is restricted by compressional stresses. Jaeger and Cook listed various elaborations of the plane Griffith theory, all of which enhance the strength in the third quadrant.

\section{Maximum strain-energy dissipation criterion}

The deformation-mechanism maps given by Ashby and Frost (1982) suggest that both dynamic recrystallization and crystal-boundary melting may be important at stresses above those which can be accommodated by power-law creep. A criterion is postulated based on a maximum allowable rate of strain-energy dissipation in the ice before failure. The work done at any point in the material is given by:

$$
\text { Power density }=\frac{1}{2} \epsilon_{i j} \sigma_{i j}
$$

where $\epsilon_{i j}$ is the strain-rate tensor. In the principal-axis system, and in the absence of anisotropy, the cross terms are lost. Using the power flow law (Equation (9)) and applying the free-surface boundary condition we find

$$
\sigma_{\mathrm{t}}^{4}=\left(\sigma_{1 \text { surf }}{ }^{2}+\sigma_{2 \text { surf }}{ }^{2}\right)\left(\sigma_{1 \text { surf }}^{2}+\sigma_{2 \text { surf }}^{2}-\sigma_{1 \text { surf }} \sigma_{2 \text { surf }}\right)
$$

which has a similar elliptical shape to that of the maximum octahedral shear-stress criterion but has a slightly smaller axial ratio.

Figure 3 shows the failure envelopes described above scaled to have tensile strengths (where one SPPS is zero) of $200 \mathrm{kPa}$. The maximum octahedral shear-stress, Coulomb and maximum strain-energy dissipation criteria give rise to envelopes that are quite similar. It seems unlikely at the outset that our analysis of the distribution of crevassing indicated on the failure maps could determine the microscopic mechanism for crevassing.
Fortunately, the converse is also true; a knowledge of the precise mechanism of failure is relatively unimportant in predicting the likelihood of crevassing.

\section{ANALYSIS OF DATA SOURGES}

The principal strain rates on the surface of a glacier are commonly determined by measuring the deformation of a "strain element" formed by the fixing of markers to the ice surface (Nye, 1959). The principal strain rates obtained in this way give an areal average of the surface strain rate within the strain element. A second method for estimating principal strain rates, used by a number of workers (e.g. Holdsworth, 1969; Meier and others, 1974) involves the measurement of the ice-surface velocity at various points and then the production of contour maps of the horizontal derivatives of velocity. From these, the magnitudes of principal strain rates at interpolation points are estimated. Although more rapid in some circumstances, this method is inherently less precise than direct measurement of deformation. The interpretation of the area sampled by this method is also much less certain.

The failure maps are expressed in terms of principal stresses. As a result, the strain-rate measurements must be converted using an appropriate flow law. The constitutive relation used here is that most widely applied to glacier ice: the power law for creep proposed by Glen (1955). The strain-rate tensor $\epsilon_{i j}$ is given by:

$$
\epsilon_{i j}=A \sigma^{n-1} \sigma_{i j}^{\prime}
$$

where the effective shear stress $\sigma$ is

$$
2 \sigma^{2}=\sigma_{i j}^{\prime} \sigma_{i j}^{\prime} . \quad \text { (summation convention) }
$$

The parameters $A$ and $n$ in this relation have been derived from a variety of measurements made on dense glacier ice. The exponent $n$ is taken to be 3 , and the rate factor $A$ is assumed to take the Arrhenius form of a thermally activated mechanism:

$$
A=A_{0} \exp \left\{Q / R\left(\left(1 / T_{0}\right)-(1 / T)\right)\right\}
$$

where $R$ is the gas constant, $Q$ is the activation energy and $T$ is the temperature of the ice in Kelvin, assumed to be given by the measured $10 \mathrm{~m}$ temperature. Below $-10^{\circ} \mathrm{C}$, the deformation is assumed to be via dislocation glide within the crystals, whereas above $-10^{\circ} \mathrm{C}$ it is assumed to be dominated by crystal-boundary creep. Paterson's data (1981, p. 39) suggest that if $T_{0}=$ $263.16 \mathrm{~K}$, then $A_{0}$ should be around $5.2 \times 10^{-25} \mathrm{~s}^{-1}$ $\mathrm{Pa}^{-3}$, with $Q=60 \mathrm{~kJ} \mathrm{~mol}^{-1}$ below $-10^{\circ} \mathrm{C}$, and $Q=139 \mathrm{~kJ}$ mol ${ }^{-1}$ between $-10^{\circ} \mathrm{C}$ and the melting point.

Applying the ice-surface boundary condition and rearranging relations (Equations (2), (9) and (10)), we obtain:

$$
\sigma_{1 \text { surf }}^{\prime}{ }^{3}=\epsilon_{1 \text { surface }}{ }^{3} /\left[A\left(\epsilon_{1 \text { surf }}{ }^{2}+\epsilon_{1 \text { surf }} \epsilon_{2 \text { surf }}+\epsilon_{2 \text { surf }}{ }^{2}\right)\right]
$$

by which the stresses may be calculated for measured strain rates.

In most of the analyses used here, the estimates of the error in strain-rate measurements have been made from a consideration of the survey techniques. Authors have 
generally given a single value for the uncertainty applying to both principal strain rates and it is assumed that the error on each principal strain rate constitutes an uncorrelated random error (for exception, see Appendix 1, Rutford Ice Stream). These uncertainties in strain rate are converted to stress uncertainties and are included in the failure plots as error ellipses. It should be noted that, due to the form of Equation (9), which implies that viscosity tends to infinity as stress tends to zero, low measured strain rates produce large-percentage uncertainties in stress.

\section{CREVASSE LOCATION}

In order to determine the relation between measurements of strain rate and the occurrence of crevassing, a measurement of crevasse activity is specified to be associated with each measurement of strain rate. Ideally, this would be some rigorous function taking account of the distance to, and rate of opening of, all the local crevasses. Sufficient data to perform this type of classification are not available and a much simpler classification is adopted. Only three classes of crevasse activity are defined:

(a) "Uncrevassed", where there is no evidence for crevassing or other surface deformation (e.g. folding or thrusting) within two ice thicknesses of the strain element when Nye's method is used, or within four ice thicknesses of the interpolation point when the velocity derivative method is used.

(b) "Crevassed", where there is direct evidence of crevassing within the strain element when Nye's method is used or within two ice thicknesses of the interpolation point when the velocity-derivative method is used.

(c) "Close to crevassing", where crevassing may be imminent, an intermediate class has been introduced to make allowance for sites This classification is used if crevassing occurs within two ice thicknesses of the strain element when Nye's method is used, or four ice thicknesses of the interpolation point when the velocity-derivative method is used. It is not intended that these sites be used when defining the failure envelope, but that they should give an indication of the values close to the boundaries of crevassed zones.

It is possible that the crevasse classification of a small fraction of the points in each data set is in error, perhaps where crevassing remains undetected or where other surface features (aeolian or meltwater in origin) have been identified incorrectly as crevasses. Care is taken not to base the failure envelopes on the most extreme uncrevassed points where these lie well beyond the majority. Because there is a degree of subjectivity in the classification, there is little that can be done to quantify the confidence limits rigorously. By inspection of the data, it is assumed that up to $5 \%$ of the data may be classified incorrectly.

Potential sources of crevasse-location data are satellite

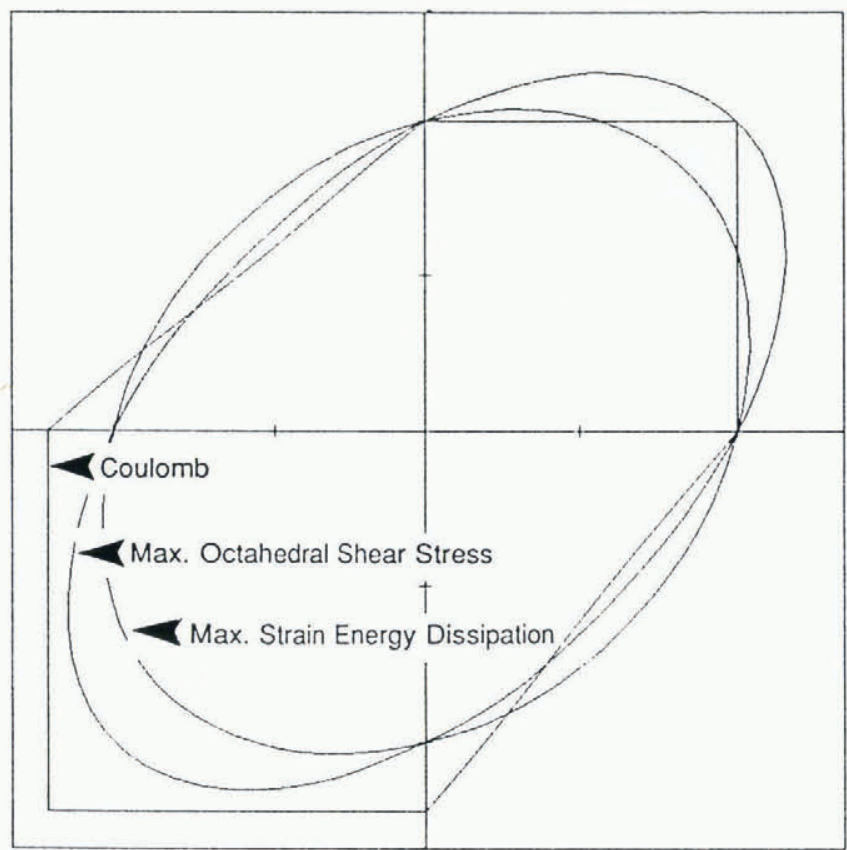

Fig. 3. Comparison of theoretical failure envelopes on the SPPS axial system.

imagery, aerial photography and reports from field parties. The reliability of the data obtained from such sources is noticeably variable. Comparing results from the different sources where they overlap, aerial photography appears to be the most reliable, because, if taken with low sun elevation, it combines high spatial resolution and high contrast. Perhaps surprisingly, the recorded observations of ground parties often do not make reference to crevassing that is clearly visible on aerial photography. This is particularly the case where crevasses are not open and so do not inhibit surface travel. Such features may be unnoticeable from the ground or mistaken for windblown sastrugi. They often appear as strong linear features on aerial photographs and occur in narrow bands parallel to the flow direction at the boundaries of ice streams and ice shelves. Satellite imagery can cover very large areas of inaccessible ice surface and is a useful source of data on crevasse location. Landsat MultiSpectral Scanner (MSS) imagery, however, with a resolution of $70 \mathrm{~m}$, is capable of distinguishing only areas of intense crevassing. Imagery from the Landsat Thematic Mapper and SPOT, with resolutions of 30 and $10 \mathrm{~m}$, respectively, is better and may even show individual crevasses. Crevasses can remain visible on the surface of an ice mass for many years and may move some distance through the stress field within their lifespan.

Using the data sources above, it is not possible to determine reliably the state of activity of any area of crevassing; crevassing may either be active or a relict of upstream activity. No distinction is made in this study between these types. This has important consequences for the interpretation of the failure maps presented later.

An inability to distinguish between active and relict crevasses means that data points defined as "crevassed" may be associated either with active crevassing (and should fall outside the failure envelope) or with "relict" crevassing (which exists in quiescent areas at the time of measurement) and may fall inside the envelope. Failure 


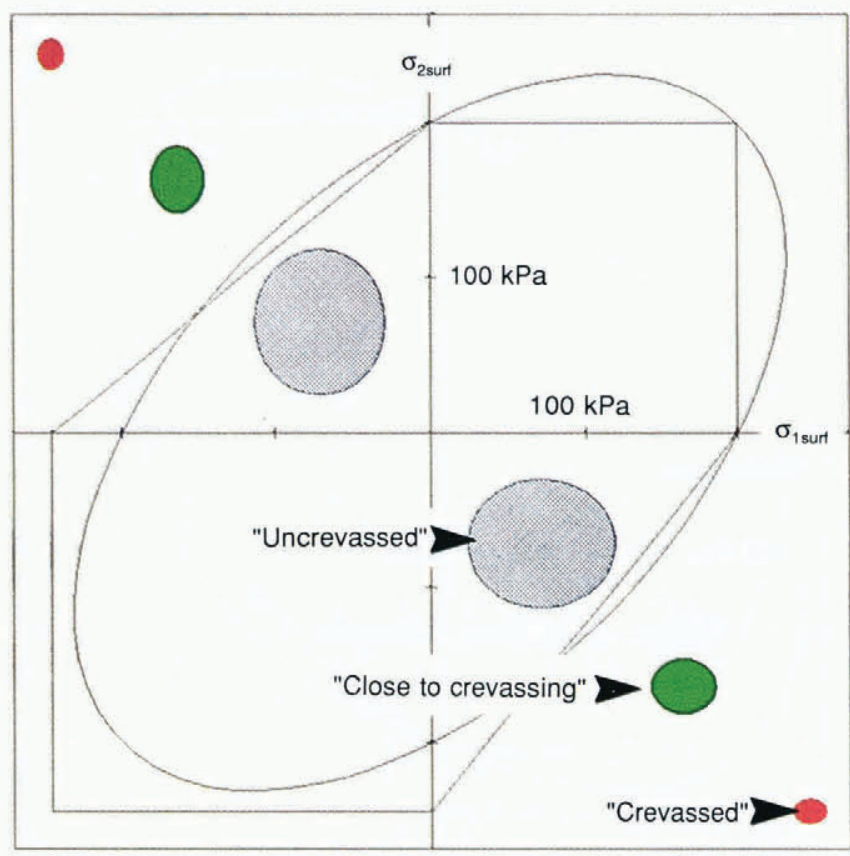

Fig. 4. Schematic key to the failure maps. Note that ticks are given at $100 \mathrm{kPa}$ intervals along the axes on all failure maps.

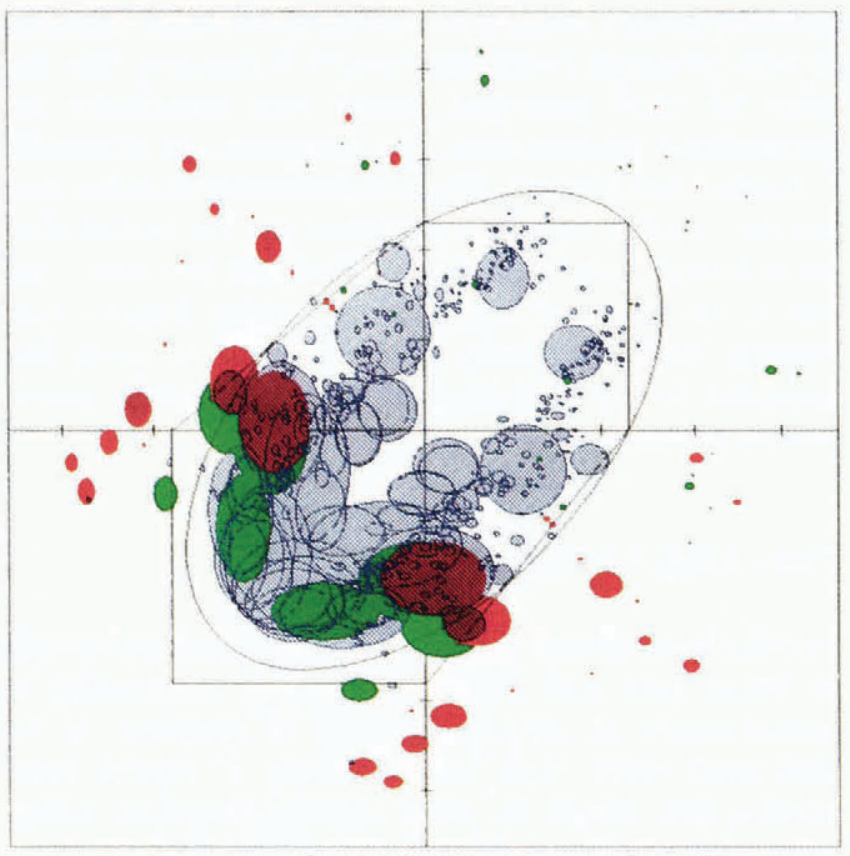

Fig. 5. Failure map for Rutford Ice Stream, Antarctica.

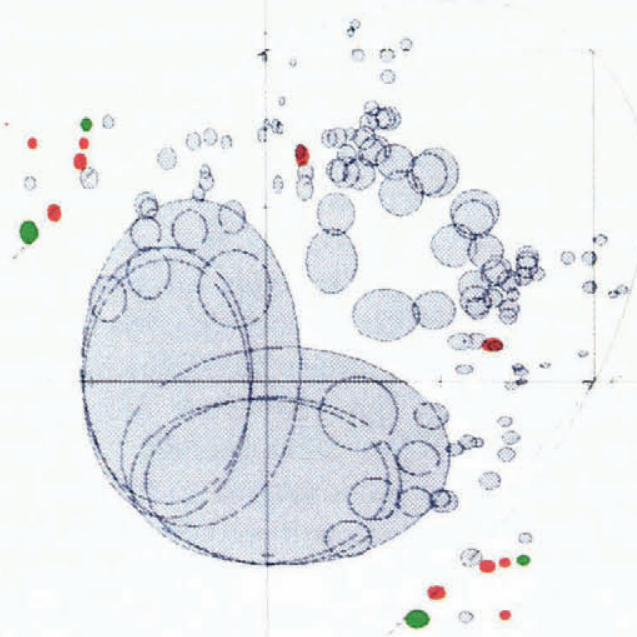

Fig. 6. Failure map for Ross Ice Shelf, Antarctica.

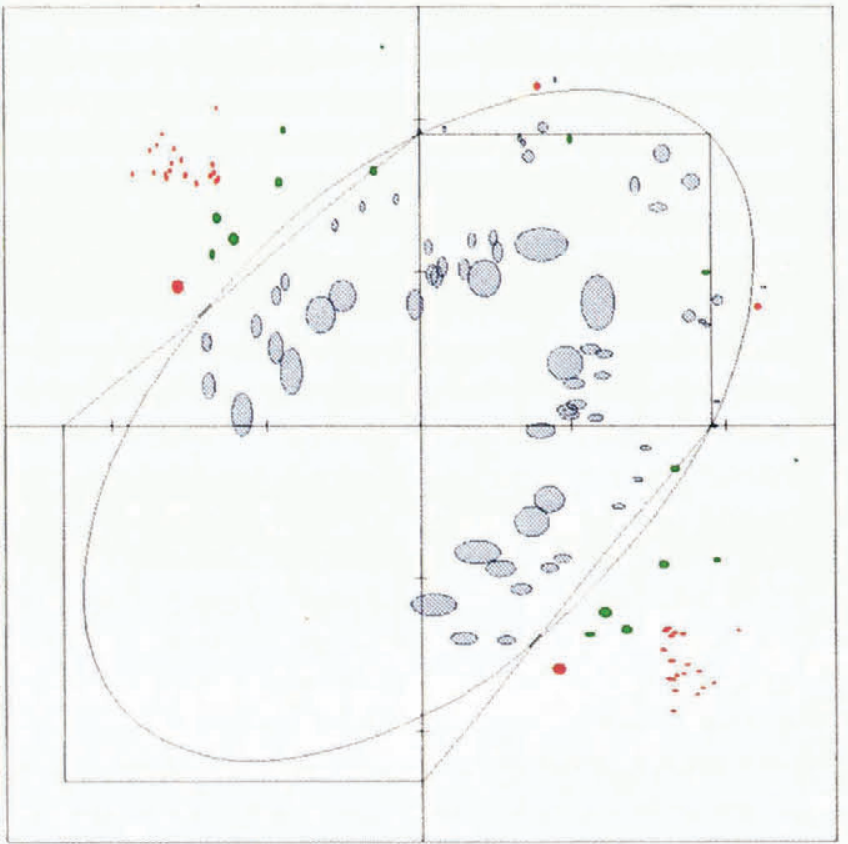

Fig. 7. Failure map for Siple Coast, Antarctica.

envelopes should be drawn to include the "uncrevassed" points, not to exclude "crevassed" points. Some "crevassed" data points, associated with "relict" crevassing, will inevitably be included in the envelope.

\section{FAILURE MAPS}

Failure maps for the following areas are shown in Figures 4-10: Rutford Ice Stream, Antarctica; Ross Ice Shelf, Antarctica; Siple Coast, Antarctica; Bay of Whales, Antarctica; Austfonna, Svalbard; and Hintereisferner, Austria. A brief description of each data set is given in

Appendix 1. Each map includes examples of the maximum octahedral shear-stress envelope and Coulomb-criterion envelope, scaled to best fit the data points, i.e. to enclose (to the nearest whole number) $95 \%$ of the uncrevassed points, allowing for up to $5 \%$ of the uncrevassed sites to be classified incorrectly. Since the failure surface must be symmetrical with respect to interchange of the principal directions, there is no particular significance in the assignment of either principal stress as $\sigma_{1 \text { surf }}$ or $\sigma_{2 \text { surf }}$. To facilitate visualization of the failure maps, each data point is plotted with both assignments, giving symmetry across the line $\sigma_{1 \text { surf }}=\sigma_{2 \text { surf }}$. 


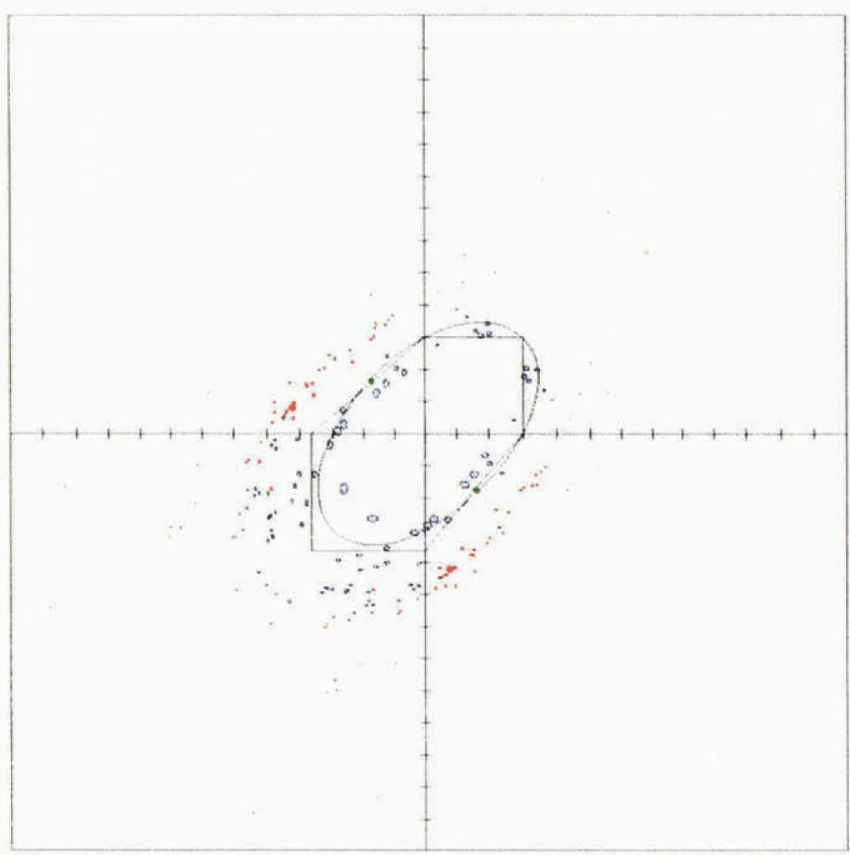

Fig. 8. Failure map for Bay of Whales, Antarctica.

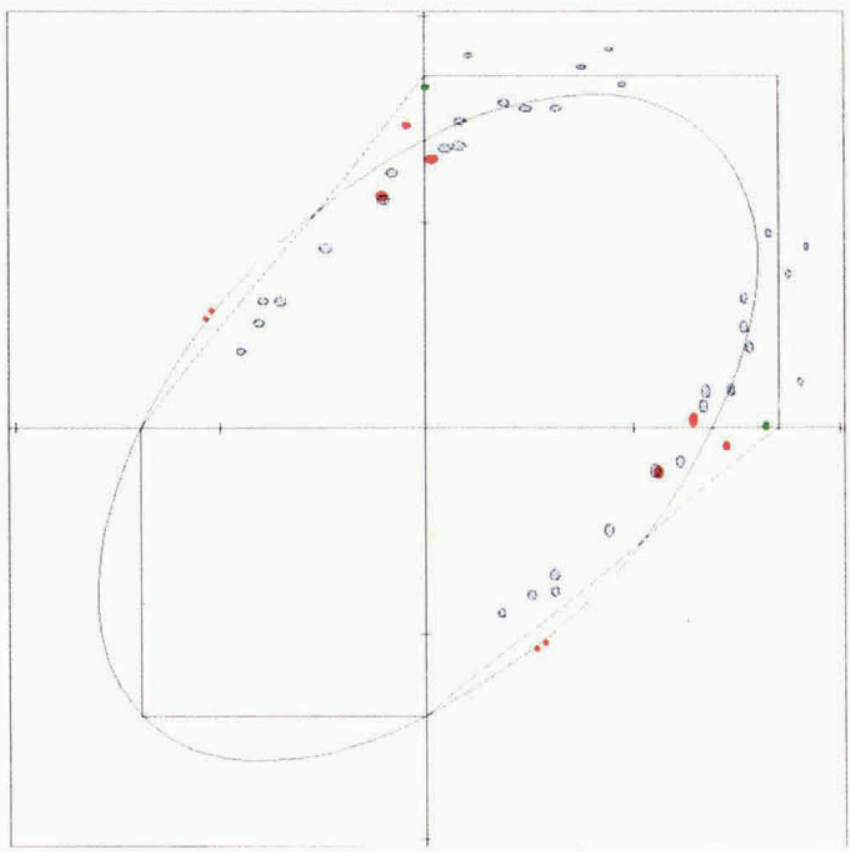

Fig. 10. Failure map for Hintereisferner, Austria.

An identical procedure was followed for a number of other data sets whose failure maps are, for the sake of brevity, not presented here. Table 1 gives an outline description and cites the sources of all the data sets used.

Only six data sets (Mizuho Plateau, Ronne Ice Shelf, Ross Ice Shelf, Rutford Ice Stream, Siple Coast and Bay of Whales) have enough strain-rate measurements to make any realistic statement about the shape of the failure envelope. By comparison with Figure 3, it will be seen that neither the plane Griffith nor maximum strainenergy dissipation envelopes give a convincing fit to the data. The distribution of points may, however, be well described by envelopes derived for both the maximum

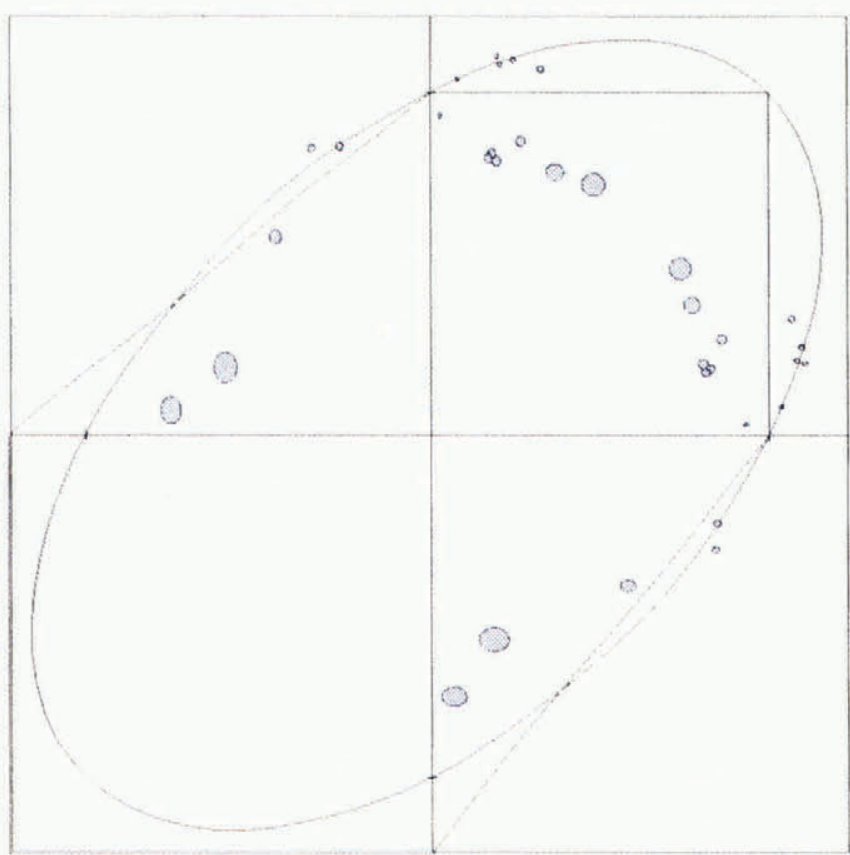

Fig. 9. Failure map for Austfonna, Svalbard.

octahedral shear-stress criterion and Coulomb criterion, and fitted by scaling for each data set.

Some data sets (Austfonna, Barnes Ice Cap, George VI Sound), which contain too few measurements to give a convincing indication of the shape of the failure envelope, are nevertheless useful for giving some indication of envelope magnitude. Assuming that the Coulomb and maximum octahedral shear-stress envelopes have the correct shape, as determined for the more-populated data sets, the preferred envelopes have been scaled to fit the limited data available.

Where a data set contains no measurements from crevassed areas (George VI Ice Shelf, Austfonna and Barnes Ice Cap), the failure map can only be used to give a lower bound on the tensile strength. Other data sets (e.g. Griesgletscher (Hambrey and Milnes, 1980); Variegated Glacier (Sharp and others, 1988)) were found to comprise only measurements from strain elements classified as crevassed. These data sets can provide no constraint on the failure envelope and were discarded.

In the data sets from the Bay of Whales and Hintereisferner (and to a lesser extent Rutford Ice Stream), the maximum octahedral shear-stress criterion appears to fail in the third (compressive) quadrant of the failure map. This is suggested by the fact that a number of values of principal strain rate from non-crevassed areas are unexpectedly large. This elongation of the failure envelope into the third quadrant would be the effect of adopting a funnel-shaped envelope of the type shown in Figure 1.

\section{VARIATION OF TENSILE STRENGTH WITH $10 \mathrm{~m}$ TEMPERATURE}

Since the rate factor $A$ in the creep flow law has a strong temperature-dependence (ice is approximately 100 times stiffer at $-30^{\circ} \mathrm{C}$ than close to its melting point), it is 


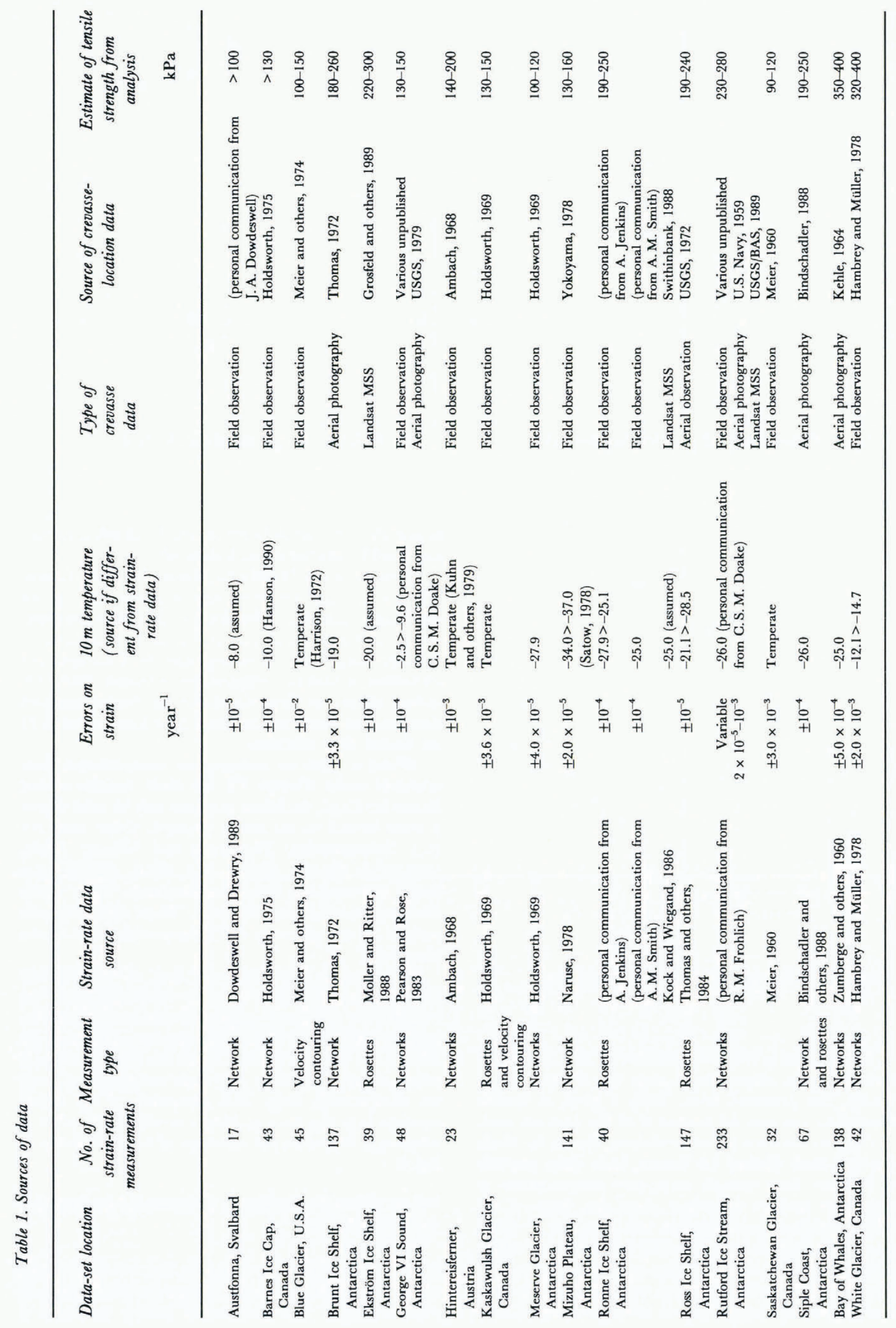




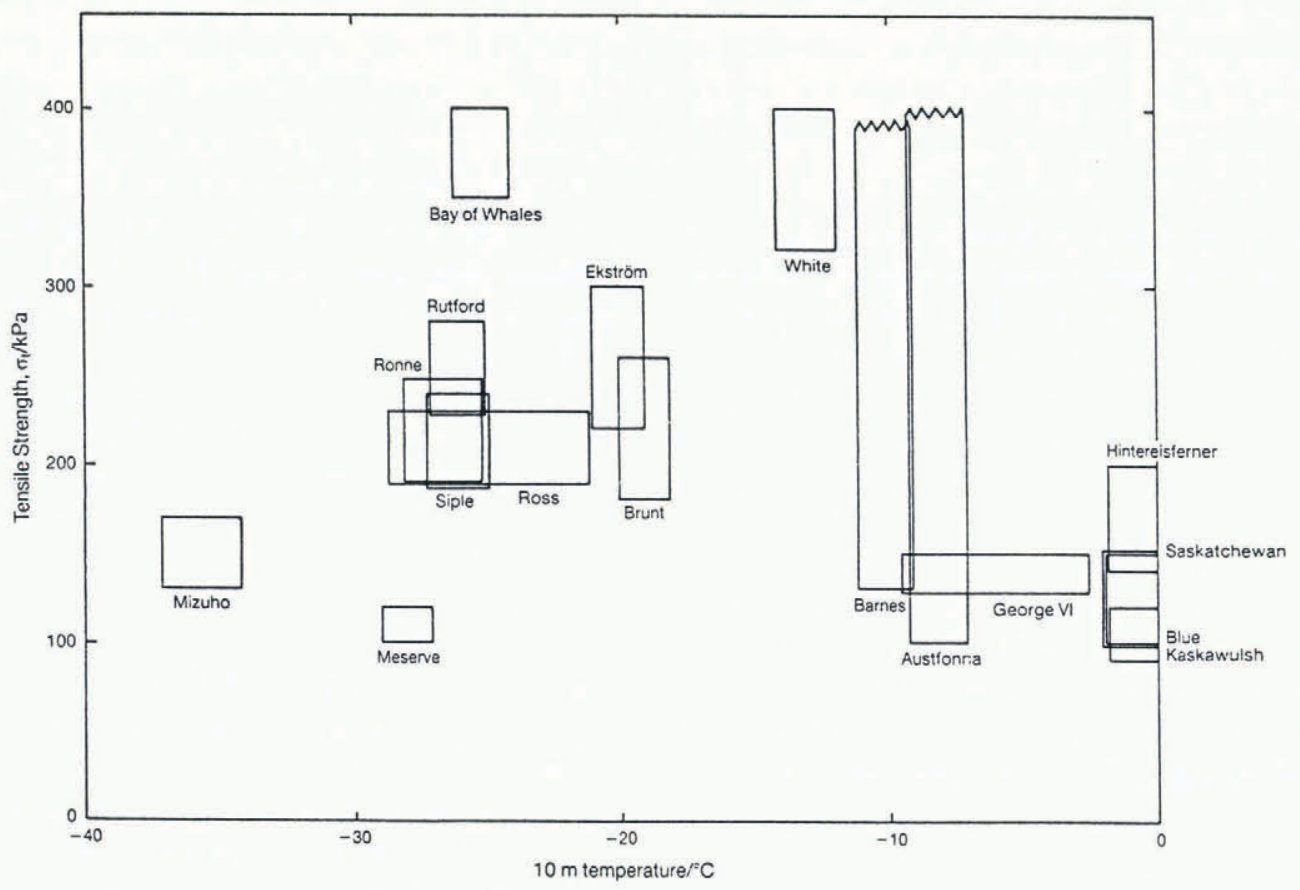

Fig. 11. The variation of tensile strength derived from failure maps with $10 \mathrm{~m}$ temperature. The width of the boxes indicates uncertainty in $10 \mathrm{~m}$ temperature and the uncertainty in tensile strength consistent with the stress data used.

reasonable to look for temperature-dependence in the tensile strength. The $10 \mathrm{~m}$ temperature is the only parameter relating to temperature recorded routinely by glaciologists. It is commonly understood to give an approximation to the mean annual air temperature where seasonal melting does not occur.

The variation of tensile strength with $10 \mathrm{~m}$ temperature is derived from an estimation of the failure envelope on failure maps (Fig. 11). Although the critical strain rate for failure varies over the temperature range by a factor of approximately 500 , the variation of tensile strength over the same range is probably no more than a factor of 5 , confirming that most of the variation between localities can be explained by changes in temperature. There is no discernible systematic variation of tensile strength with $10 \mathrm{~m}$ temperature. With temperature effects removed, the residual variations seen in Figure 11 may be assigned to variations in other parameters (e.g. crystal size; Sunder and Wu, 1990), impurity content, strain history, firn density (porosity), accumulation rate or sensitivity of the method used for crevasse location). Unfortunately, no parameters relating to firn fabric are recorded routinely with strain data, so an estimation of the relative importance of each factor is not currently possible. Furthermore, Hooke (1981) showed that rate factors $\left(A_{0}\right)$ for the creep of ice derived from different sources varied by at least a factor of 4 . This is a similar variation to that seen here in derived tensile strength and, therefore, variations in the flow-law parameters could easily account for this variation in derived tensile strength.

There is no systematic variation of tensile strength with the type of data used to locate crevassing (Landsat imagery, aerial photographs or ground-based observation); it is unlikely, therefore, that the derived tensile strength is influenced significantly by the resolution of the data.

It should be noted that the data from Blue Glacier,
Saskatchewan Glacier and White Glacier came from below the firn line and hence referred to fractures in solid glacier ice. It is perhaps surprising that there is no systematic difference in tensile strength derived from these data sets and those derived from measurements made in firn. This result may be an indication that crevasse formation is controlled by similar microscopic mechanisms to those responsible for creep and that the two phenomena share a similar Arrhenius temperaturedependence.

\section{APPLIGATIONS}

Mathematical models of ice-sheet dynamics must be verified before their predictions of the response to climate change can be accepted. However, available methods with which to make this verification are at present limited. Surface measurements of velocity and strain rate are time-consuming to obtain and give only sparse coverage. The relationship developed here may allow workers to obtain ice-sheet stress data directly from aerial and satellite observation of crevasse fields, with considerably better spatial coverage than ground-based measurements.

Most of the ice lost from Antarctica is by iceberg calving, a little studied and poorly understood process. Most calving is believed to have been initiated by the formation of a crevasse by tension at the surface, generated by the vertical moment at the ice front. There are, however, obvious exceptions where an iceberg calves by failure along a pre-existing line of weakness. Analyses of the process of calving (e.g. Reeh, 1968; Fastook and Schmidt, 1982; Hughes, 1983) have been hampered by the lack of a failure criterion of the type presented above.

The recent collapse of Wordie Ice Shelf, Antarctica, has been ascribed to atmospheric warming (Doake and 
Vaughan, 1991). This has altered the net surface mass balance from accumulation to ablation, thereby removing the stabilizing effect of new accumulation and effectively enhancing crevassing by allowing zones of weakness to develop in the ice shelf. It is, however, unlikely that atmospheric warming of a few degrees Centigrade will have a similar effect on the calving rate of the RonneFilchner and Ross Ice Shelves, which are believed to stabilize the West Antarctic ice sheet (Mercer, 1978). These ice shelves exist at a considerably lower mean annual air temperature and thus will continue to have net accumulation even with a rise of several degrees Centigrade in mean annual air temperature. The results of this study suggest that fracture strength is unlikely to be affected by a small change in temperature within the ice column or surface layers, per se. An increase in calving rate of these ice shelves would only occur if there were an accompanying change in the stress regimes of the ice shelves, due to thinning or increased flow velocities.

\section{SUMMARY}

The assumption central to this study is that crevasse formation can be predicted by a simple non-hysteretic law based on the stress field within the ice sheet. If it were possible to distinguish active from relict crevasses reliably, the derivation of the failure envelopes could be made less subjective. The formation of crevassing within each data set has been described adequately by both the maximum octahedral shear stress (von Mises) criterion and the Coulomb criterion (assuming $\mu=0.1$ ) calculated for the ice at depth and assuming no variation of strain rate with depth. This agreement is, however, not diagnostic of the mechanism involved. The critical strain rate for failure varies by a factor of 500 over the sites studied but there is no systematic variation of tensile strength, which varies between 90 and $320 \mathrm{kPa}$ with $10 \mathrm{~m}$ temperature. This indicates that the thermal activation energies of creep and failure are closely related. Care should be taken not to interpret these values as a failure criterion for deep glacier ice, because most of the data in this study were derived from crevasses in a low-density firn layer. The variation in tensile strength could be ascribed to differences in crystal structure, impurity content, density profiles or other local variables. However, because determinations of the rate constant in the flow law vary by a similar amount, the variation in tensile strength could be ascribed to uncertainty in the strain-rate/stress conversion.

\section{ACKNOWLEDGEMENTS}

I am very grateful to C. S. M. Doake, R. M. Frolich, E. M. Morris, J. G. Paren and others, with whom I have had fruitful discussions about this work, and to C.M. Denton for useful comments on the manuscript.

\section{REFERENCES}

Ambach, W. 1968. The formation of crevasses in relation to the measured distribution of strain-rates and stresses. Arch. Meteorol. Geophys. Bioclimatol., Ser. A, 17, 78-87.
Ashby, M.F. and H.J. Frost. 1982. Deformation-mechanism maps: the plasticity and creep of metals and ceramics. Oxford, Pergamon.

Bindschadler R. A., P. L. Vornberger, S. N. Stephenson, E. P. Roberts, S. Shabtaie and D. R. MacAyeal. 1988. Ice-shelf flow at the boundary of Crary Ice Rise, Antarctica. Ann. Glaciol., 11, 8-13.

Butkovich, T.R. 1954. Ultimate strength of ice. SIPRE Res. Pap. 2.

Doake, C.S. M. and D.G. Vaughan. 1991. Rapid disintegration of the Wordie Ice Shelf in response to atmospheric warming. Nature, 350(6316), 328-330.

Dowdeswell, J. A. and D. J. Drewry. 1989. The dynamics of Austfonna, Nordaustlandet, Svalbard: surface velocities, mass balance, and subglacial meltwater. Ann. Glaciol., 12, 37-45.

Fastook, J. L. and W.F. Schmidt. 1982. Finite element analysis of calving from ice fronts. Ann. Glaciol., 3, 103106.

Frolich, R. M., D. G.Vaughan and C. S. M. Doake. 1989. Flow of Rutford Ice Stream and comparison with Carlson Inlet, Antarctica. Ann. Glaciol., 12, 51-56.

Glen, J.W. 1955. The creep of polycrystalline ice. Proc. $R$. Soc. London, Ser. A, 228(1175), 519-538.

Grosfeld, K., H. Hinze, R. Ritter, H. W. Shenke, J. Sievers and F. Thyssen. 1989. Ekströmisen, Antarktis $1: 500000$. Maps of ice shelf kinematics. Frankfurt, Institut für Angewandte Geodäsie.

Hallam, S. D. and M. F. Ashby. 1990. Compressive brittle fracture and the construction of multi-axial failure maps. In Barber, D.J. and P. G. Meredith, eds. Deformation processes in minerals, ceramics and rocks. London, Unwin Hyman, 84-108.

Hambrey, M.J. and F. Müller. 1978. Structures and ice deformation in the White Glacier, Axel Heiberg Island, NW Territories, Canada. F. Glaciol., 20(82), 41-66.

Hambrey M.J., A. G. Milnes and H. Siegenthaler. 1980. Dynamics and structure of Griesgletscher, Switzerland. J. Glaciol., 25(92), 215-228.

Hanson, B. 1990. Thermal response of a small ice cap to climatic forcing. 7. Glaciol., 36(122), 49-56.

Harrison, W.D. 1972. Temperature of a temperate glacier. 7. Glaciol., 11(61), 15-29.

Holdsworth, G. 1969. Primary transverse crevasses. $\mathcal{J}$. Glaciol., 8(52), 107-129.

Holdsworth, G. 1975. Deformation and flow of Barnes Ice Cap, Baffin Island. Ottawa, Environment Canada. Inland Water Directorate. (Scientific Series 52.)

Hooke, R. LeB. 1981. Flow law for polycrystalline ice in glaciers: comparison of theoretical predictions, laboratory data, and field measurements. Rev. Geophys. Space Phys., 19(4), 664-672.

Hughes, T. 1983. On the disintegration of ice shelves: the role of fracture. 7. Glaciol., 29(101), 98-117.

Jaeger, J. C. and N. G. W. Cook. 1979. Fundamentals of rock mechanics. Third edition. London, Chapman and Hall.

Jones, S.J. 1982. The confined compressive strength of polycrystalline ice. J. Glaciol., 28(98), 171-177.

Kehle, R. O. 1964. Deformation of the Ross Ice Shelf, Antarctica. Geol. Soc. Am. Bull., 75, 259-286.

Kock, H. and A. Wiegand. 1986. Glaciological geodesy on Filchner Ice Shelf 1983-86. In Kohnen, H., ed. 
Filchner-Ronne-Ice-Shelf-Programme, Report No. 3. Bremerhaven, Alfred-Wegener-Institute, 37-42.

Kuhn, M., G. Kaser, G. Markl, H. Wagner and H. Scheider. 1979. 25 Jahr Massenhaushaltsuntersuchungen am Hintereisferner. Innsbruck, Innsbruck University. Institut für Meteorologie und Geophysik.

MacAyeal, D. R., S. Shabtaie, C. R. Bentley and S. D. King. 1986. Formulation of ice shelf dynamic boundary conditions in terms of a Coulomb rheology. 7. Geophys. Res., $91(\mathrm{~B} 8), 8177-8191$.

Meier, M.F. 1958. The mechanics of crevasse formation. International Association of Scientific Hydrology Publication 46 (General Assembly of Toronto 1957 - Snow and Ice), 500-508.

Meier, M.F. 1960. Mode of flow of Saskatchewan Glacier, Alberta, Canada. U.S. Geol. Surv. Prof. Pap. 351.

Meier, M. F., W. B. Kamb, C. R. Allen and R. P. Sharp. 1974. Flow of Blue Glacier, Olympic Mountains, Washington, U.S.A. J. Glaciol., 13(68), 187-212.

Mercer, J.H. 1978. West Antarctic ice sheet and $\mathrm{CO}_{2}$ greenhouse effect: a threat of disaster? Nature, $271(5643), 321-325$.

Möller, D. and B. Ritter. 1988. Glacial geodetic contributions to the mass balance and dynamics of ice shelves. Ann. Glaciol., 11, 89-94.

Nadreau, J. P. and B. Michel. 1986. Yield and failure envelope for ice under multiaxial compressive stresses. Cold Reg. Sci. Technol., 13(1), 75-82.

Naruse, R. 1978. Studies of the ice sheet flow and local mass budget in Mizuho Plateau, Antarctica. Contrib. Inst. Low Temp. Sci., Ser. A 28, 1-54.

Nye, J. F. 1959. A method of determining the strain-rate tensor at the surface of a glacier. 7 . Glaciol., 3(25), 409419.

Paterson, W.S.B. 1981. The physics of glaciers. Second edition. Oxford, etc., Pergamon Press.

Pearson, M.R. and I.H. Rose. 1983. The dynamics of George VI Ice Shelf. Br. Antarct. Surv. Bull. 52, 205220.

Perla, R., T.M.H. Beck and T. T. Cheng. 1982. The shear strength index of alpine snow. Cold Reg. Sci. Technol., 6(1), 11-20.

Ramsay, J. G. 1967. The folding and fracturing of rocks. New York, McGraw-Hill.

Reeh, N. 1968. On the calving of ice from floating glaciers and ice shelves. 7. Glaciol., 7(50), 215-232.

Rist, M. A., S. A. F. Murrel and P. R. Sammonds. 1988. Experimental results on the failure of polycrystalline ice under triaxial stress conditions. In Saeki, H. and K.i. Hirayami, eds. Proceedings of the Ninth International Symposium on Ice, 23-27 August 1988, Sapporo, Japan. Vol. 1. Delft, International Association for Hydraulic Research, 118-127.

Satow, K. 1978. Distribution of $10 \mathrm{~m}$ temperatures in Mizuho Plateau. Mem. Natl. Inst. Polar Res. Spec. Issue 7, 63-71.

Schulson, E. M., P. N. Lim and R. W. Lee. 1984. A brittle to ductile transition in ice under tension. Philos. Mag., 49A(3), 353-363.

Schulson, E. M., I. Baker, C. D. Robertson, R. B. Bolon and R.J. Harnimon. 1989. Fractography of ice. $\mathcal{F}$. Mater. Sci. Lett., 8(10), 1193-1194.
Sharp, M., W. Lawson and R.S. Anderson. 1988. Tectonic processes in a surge-type glacier. 7 . Struct. Geol., 10(5), 499-515.

Sunder, S.S. and M.S. Wu. 1990. Crack nucleation due to elastic anisotropy in polycrystalline ice. Cold Reg. Sci. Technol., 18(11), 29-47.

Swithinbank, C. M. W. 1988. Satellite image atlas of the glaciers of the world. Antarctica. U.S. Geol. Surv. Prof. Pap. 1386-B.

Thomas, R. H. 1972. The dynamics of ice shelves. (Ph.D. thesis, University of Cambridge.)

Thomas, R. H., D. R. MacAyeal, D. H. Eilers and D. R. Gaylord. 1984. Glaciological studies on the Ross Ice Shelf, Antarctica, 1973-1978. Antarct. Res. Ser., 42, 2153.

USGS. 1972. Sketch map of Ross Ice Shelf, Antarctica. 1: 1000000. Reston, VA, United States Geological Survey.

USGS. 1979. Antarctica sketch map, Palmer Land. 1:500000. Reston, VA, United States Geological Survey.

USGS/BAS. 1989. Rutford Ice Stream, Antarctica. Satellite image map. 1:250000. Reston, VA, United States Geological Survey/Cambridge, British Antarctic Survey.

U.S. Navy. 1959. Trimetrogon photography. TMA 568 F32. Oros Data Center, Sioux Falls, U.S.A.

Weertman, J. 1973. Can a water-filled crevasse reach the bottom surface of a glacier? International Association of Scientific Hydrology Publication 95 (Symposium at Cambridge 1969 - Hydrology of Glaciers), 139-145.

Yokoyama, K. 1978. Distribution of surface structures of the ice sheet in Mizuho Plateau. Mem. Natl. Inst. Polar Res. Spec. Issue 7, 26-36.

Zumberge, J.H., M. Giovinetto, R. Kehle and J. Reid. 1960. Deformation of the Ross Ice Shelf, near the Bay of Whales, Antarctica. IGY Glaciol. Rep. 3.

The accuracy of references in the text and in this list is the responsibility of the author, to whom queries should be addressed.

\section{APPENDIX}

A selection of the data sets used in this study are outlined below. For reasons of brevity, only data sets of particular interest or those that are generally representative are included.

\section{Austfonna, Svalbard}

Dowdeswell and Drewry (1989) described a triangulation network on Austfonna which stretched from the ice divide towards the sea until nearby crevassing made continuation of the network too hazardous. No crevasses were seen within the bounds of the triangulation network (personal communication from J. Dowdeswell). Since there are no crevassed points in this data set, it can only provide a lower limit on the magnitude of the tensile strength.

\section{Hintereisferner, Austria}

Ambach (1968) described the location of 23 principal strain-rate measurements in relation to observations of 
surface crevassing on Hintereisferner and Langtaufererjochferner, at an altitude of $2750 \mathrm{~m}$ in the Oetztal Alps of Austria. He calculated the stresses associated with strainrate measurement using a method described by Nye (1959). Unfortunately, the temperature used was not given. For the sake of consistency, the stresses have been recalculated using the power flow-law inversion given above, assuming the glacier is temperate. This data set allows a good estimate of the tensile strength because some areas of active crevassing are definitely covered by the strain elements.

\section{Ross Ice Shelf, Antarctica}

Thomas and others (1984) reported the results of the Ross Ice Shelf Glaciological and Geophysical Project, which made measurements on a regular grid over the ice shelf. Both strain rates and $10 \mathrm{~m}$ temperature were measured. The location of crevassing is taken from the U.S. Geological Survey (USGS) sketch map of the area based on aerial observation and photographs.

\section{Rutford Ice Stream, Antarctica}

Rutford Ice Stream is around $40 \mathrm{~km}$ wide, $150 \mathrm{~km}$ long and $2000 \mathrm{~m}$ thick. It flows into Ronne Ice Shelf from the West Antarctic ice sheet. Data from a triangulation network of over 200 strain elements have been collected by British Antarctic Survey parties between 1975 and 1987 (Frolich and others, 1989). The ice stream flows in a bedrock trough bounded on one side by the Ellsworth Mountains, where three of the five transverse arms of the network extended well into noticeably crevassed zones. On the other side, Fletcher Promontory forms a wider boundary. On only two of the transverse arms of the scheme were a few sparse crevasses seen by the ground parties. However, USGS aerial trimetrogon photography maps of the area show clearly a band of crevassing or "stress lines" along the boundary. Examination of the original photographs shows that, although no open crevasses are visible, there are many subtle linear features on the surface of the ice that are oriented roughly parallel to the flow boundary. It would seem likely that these are deformational in origin, although the mechanism giving rise to them is not clear. A more recent map (USGS/BAS, 1989), derived from Landsat MSS imagery, shows no crevassing on this side of the ice stream. The detailed reports of crevasse sightings made by the various groundbased field parties have also been used to classify the strain elements.

For this data set, each principal strain rate was calculated as a least-squares solution to the overdetermined set of measurements in the survey. This procedure enabled estimation of the uncertainties in principal strain rates from the internal consistency of the measurements rather than the experimental method, which is more satisfactory. This method of calculation also enabled a determination of the covariance of the principal strain measurements. Numerically, the covariance was always positive and similar in magnitude to the uncertainty in the principal strains, indicating that a positive error in one principal strain would be likely to be accompanied by a similar positive error in the other. This is perhaps not surprising in this data set, where errors in length determination were few and pivotal to the survey reduction. Errors in measurements of angles are likely to give a negative covariance, because an error in the angle would probably increase one principal strain rate whilst decreasing its partner. Since there are a large number of both crevassed and uncrevassed points in this data set, the possible failure envelope is well constrained. The distribution of points is well fitted by an elliptical envelope. The pattern is disturbed by the extreme outlier in the second quadrant which remains a puzzle.

\section{Siple Coast, Antarctica}

Considerable data, collected by numerous workers on the Siple Coast, West Antarctica, were collated by Bindschadler and others (1988). The survey data come mostly from isolated rosettes, but one particularly interesting triangulation network was installed across the active shear zone from the Ross Ice Shelf on to Crary Ice Rise. Bindschadler and others also showed a digest of various aerial photographs, with positions of stakes and locations of crevasses, and many $10 \mathrm{~m}$ temperatures.

\section{Bay of Whales, Antarctica}

These data were collected between 1957 and 1960 in the locality of Camp Michigan on the Ross Ice Shelf for a study of ice deformation in relation to geological analogues. The area covered was only a few kilometres across, but the use of skis for travel allowed access to some highly crevassed areas, giving more measurements of strain in crevassed regions in this data set than any collected since on a polar ice mass. Strain data come from a large-scale triangulation network with inter-station distances of the order of $200 \mathrm{~m}$. The stations are marked on the aerial photograph mosaic given in Kehle (1964). A number of small strain-rosettes with $15 \mathrm{~m}$ leg lengths were set up in the most crevassed area studied. The locations of the stations in the strain rosettes are not given accurately in the published data and so it is difficult to determine whether the areas enclosed by the rosettes were crevassed or not. These data are therefore excluded from this analysis. The flow law used by Kehle to derive principal stresses from measured strain rates is no longer widely used, so it seems valid to re-analyse the data to maintain consistency with the other data sets analysed here.

Although Kehle's generalized failure surface gives an excellent indication of the likely failure envelope, it does not correspond to any physical model of failure and the envelope could be completely open in the third quadrant. The points on the failure map cannot be identified easily with the strain-rate measurements quoted in the paper; the total number of plotted points is greater than the number of strain-rate measurements and no indication of confidence limits is given. It is assumed that the lack of perfect symmetry about $\sigma_{1 \text { surf }}=\sigma_{2 \text { surf }}$ was an oversight during preparation of the diagram. Several algebraic mistakes exist in Kehle's paper and it is not beyond reasonable doubt that the principal strain rates quoted are systematically in error, which might explain why the derived tensile stress is so much larger than those from other data sets. 